\title{
Ações de promoção da saúde nas escolas brasileiras: uma revisão integrativa
}

\author{
Health promotion actions in brazilian schools: an integrative review \\ Acciones de promoción de la salud en las escuelas brasileñas: una revisión integrativa
}

Recebido: 18/01/2021 | Revisado: 21/01/2021 | Aceito: 25/01/2021 | Publicado: 31/01/2021

Tatiane Marinz de Souza Luquez
ORCID: https://orcid.org/0000-0001-8895-9950
Universidade Federal Fluminense, Brasil
E-mail: tatianemarinz@ gmail.com
Vera Maria Saboia
ORCID: https://orcid.org/0000-0003-0382-5078
Universidade Federal Fluminense, Brasil
E-mail: verasaboia@ @uol.com.br
Ana Carolina Mendonça Meireles
ORCID: https://orcid.org/0000-0003-0802-9556
Universidade Federal Fluminense, Brasil
E-mail: anacarolinammeireles@ gmail.com
Caroline Figueiredo Moura
ORCID: https://orcid.org/0000-0002-8969-3354
Universidade Federal Fluminense, Brasil
E-mail: mouracaroline @id.uff.br
Crystiane Ribas Batista Ribeiro
ORCID: https://orcid.org/0000-0002-3026-8548
Universidade Federal Fluminense, Brasil
E-mail: crystiane.ribas@ gmail.com
Ana Luiza Dorneles da Silveira
ORCID: https://orcid.org/0000-0003-4126-7919
Universidade Federal Fluminense, Brasil
E-mail: analudorneles@gmail.com

\section{Resumo}

Objetivo: Investigar como são planejadas e desenvolvidas as ações de promoção da saúde, nas escolas do Brasil, a partir da visão de profissionais da saúde e educação. Metodologia: Revisão integrativa de natureza qualitativa, com uso dos descritores em saúde e MeSHterms nas bases de dados: LILACS e MEDLINE. Critérios de inclusão: artigos publicados no período de 2007 a 2019, disponíveis na íntegra, nos idiomas português, espanhol e inglês; e diretamente relacionado ao tema. Resultados: Foram selecionados e analisados 20 artigos científicos, que foram agrupados em três categorias: As diferentes visões de promoção da Saúde, Planejamento das ações de promoção da saúde e Desenvolvimento das ações promoção da saúde nas escolas. A maioria dos estudos revela que os profissionais confundem o termo de promoção da Saúde com prevenção de doenças. Há dificuldade em articular o planejamento e desenvolvimento das ações de promoção da saúde. Considerações Finais: O planejamento incipiente incentiva ações pontuais, descontextualizadas, focadas na prevenção de doenças e no modelo biomédico. Assim, reforça-se a necessidade dos profissionais da educação e da saúde aplicarem estratégias educacionais que facilitem e potencializem o planejamento e execução de ações de promoção da saúde no espaço escolar.

Palavras-chave: Educação em saúde; Serviços de saúde escolar; Promoção da saúde; Planejamento em saúde; Ensino.

\begin{abstract}
Objective: To investigate how health promotion actions are planned and developed in schools in Brazil, from the perspective of health and education professionals. Methodology: Qualitative integrative review, using health descriptors and MeSHterms in the databases: LILACS and MEDLINE. Inclusion criteria: articles published from 2007 to 2019, available in full, in Portuguese, Spanish and English; and directly related to the topic. Results: Twenty scientific articles were selected and analyzed, which were grouped into three categories: The different views of health promotion, Planning of health promotion actions and Development of health promotion actions in schools. Most studies reveal that professionals confuse the term health promotion with disease prevention. There is difficulty in articulating the planning and development of health promotion actions. Final Considerations: Incipient planning encourages punctual, decontextualized actions, focused on disease prevention and the biomedical model. Thus, the need for education and health professionals to apply educational strategies that facilitate and enhance the planning and execution of health promotion actions in schools is reinforced.
\end{abstract}

Keywords: Health education; School health services; Health promotion; Health planning; Teaching. 


\section{Resumen}

Objetivo: Investigar cómo se planifican y desarrollan acciones de promoción de la salud en las escuelas de Brasil, desde la perspectiva de los profesionales de la salud y la educación. Metodología: Revisión integradora cualitativa, utilizando descriptores de salud y MeSHterms en las bases de datos: LILACS y MEDLINE. Criterios de inclusión: artículos publicados de 2007 a 2019, disponibles íntegramente, en portugués, español e inglés; y directamente relacionado con el tema. Resultados: Se seleccionaron y analizaron veinte artículos científicos, que se agruparon en tres categorías: Las distintas visiones de promoción de la salud, Planificación de acciones de promoción de la salud y Desarrollo de acciones de promoción de la salud en las escuelas. La mayoría de los estudios revelan que los profesionales confunden el término promoción de la salud con prevención de enfermedades. Existe dificultad para articular la planificación y desarrollo de acciones de promoción de la salud. Consideraciones Finales: La planificación incipiente fomenta acciones puntuales, descontextualizadas, enfocadas en la prevención de enfermedades y el modelo biomédico. Reforzando la necesidad de que los profesionales de la educación y la salud apliquen estrategias educativas que potencien la planificación y ejecución de las acciones de promoción de la salud en las escuelas.

Palabras clave: Educación en salud; Servicios de salud escolar; Promoción de la salud; Planificación de la salud; Enseñanza.

\section{Introdução}

Há evidências do benefício de atividades participativas de promoção à saúde no ambiente escolar, caracterizando-se pela interação entre conhecimentos prévios e novos. Nesse processo, os conhecimentos prévios são ressignificados dentro da sua realidade e os novos conhecimentos adquirem significado para o sujeito. No entanto, ainda é um desafio desenvolver participativamente essas atividades, visto que os programas escolares implantados no Brasil permanecem fundamentados na vertente tradicional, com poucas estratégias inovadoras de ensino (Marques \& Carvalho, 2017; Lacerda, Soares, Goncalves, Lopes \& Testoni, 2013).

Há uma lacuna existente entre teoria e prática, que indica a necessidade de intervenções com metodologias progressistas e inovadoras nas práticas educativas em saúde. Muitos profissionais percebem a saúde como uma concepção de trabalho/cuidado em saúde reduzido ao corpo biológico. Desse modo, perpetuam a visão higienista e de isolamento da própria instituição em relação aos outros equipamentos do contexto em que estão inseridos. As ações educativas são executadas de forma isolada e sem articulações com contexto sociocultural (Luquez \& Sabóia, 2017).

O modelo dominante de educação na área da saúde ainda permanece centrado no ensino das doenças, por meio de aulas teóricas e estratégias de ensino-aprendizagem centradas no professor. No entanto, as propostas para um modelo inovador incluem ensino centrado na saúde, com ênfase em práticas de promoção à saúde, com estratégias centradas no aluno, que permitam autonomia na construção do conhecimento e valorização de atitudes, habilidades, além do conhecimento técnico. Ou seja, práticas educativas bem-sucedidas são aquelas que geram aprendizagem e desenvolvimento humano, porque contribuem para a expansão de afetos alegres que potencializem mentes e corpos humanos a agirem com compromisso social (Marques \& Carvalho, 2017).

Nesse contexto, há propostas inovadoras e intersetoriais, as quais têm contribuído para a criação de um cenário favorável ao debate acerca de uma Política Nacional de Saúde nas Escolas, tal como o Programa Saúde na Escola (PSE) (Farias, Ronice, Figueiredo \& Menezes Filho, 2016). Vale ressaltar que nas últimas décadas, reflexões e estudos sobre o cuidado no âmbito da saúde humana têm sido considerável. O espaço escolar vem se tornando objeto de pesquisas em destaque, principalmente quanto à sistematização de práticas, as quais são construídas e utilizadas em prol do cuidado de escolares (Silva, Sena, Gandra, Matos \& Coura, 2014).

Diante desse contexto, para conhecer como são planejadas e executadas as ações de promoção da saúde nas escolas, foi realizada uma revisão nas produções científicas com o objetivo investigar como são planejadas e desenvolvidas as ações de promoção da saúde, nas escolas do Brasil, a partir da visão de profissionais da saúde e educação. 


\section{Metodologia}

Trata-se de uma revisão integrativa de natureza qualitativa, seguindo as seis etapas inerentes ao método, são elas: estabelecimento da questão de pesquisa e objetivos da revisão; critérios de inclusão e exclusão dos artigos (seleção da amostra); categorização dos estudos; análise dos resultados; discussão e apresentação dos resultados, e síntese do conhecimento (Mendes, Silveira \& Galvão, 2008). Na pesquisa de natureza qualitativa o foco é o "significado" que as pessoas dão as coisas e a sua vida a partir da interpretação por parte dos pesquisadores com suas opiniões sobre o fenômeno em estudo, possibilitando a descrição dos dados coletados (Pereira, Shitsuka, Parreira \& Shitsuka, 2018).

Para definição da questão da pesquisa, utilizou-se a estratégia PICO, composta por três elementos, para que a pergunta fundamentasse a busca bibliográfica: o paciente, população ou problema (P), que neste estudo foram os profissionais de saúde e educação; o interesse (I), planejamento e desenvolvimento das ações de promoção da saúde; e o contexto (Co), a escola. Dessa forma, teve-se como questão norteadora: como são planejadas e desenvolvidas ações de promoção da saúde nas escolas do Brasil, a partir da visão dos profissionais de saúde e educação sobre essa temática?

A pesquisa foi conduzida por duas pesquisadoras independentes no período 06/02/2020 à 22/02/2020 nas bases de dados Literatura Latino-Americana e do Caribe em Ciências da Saúde (LILACS) e Literatura Internacional em Ciências da Saúde (MEDLINE) via portal PubMed. Os descritores foram definidos de acordo com cada base de dados consultada, sendo os Descritores em Ciências da Saúde (DeCS) na LILACS e o Medical Subject Headings (MeSH) na Medline/ Pubmed. Os DeCS e MeSH utilizados respectivamente foram: educação em saúde/ health education; serviços de saúde escolar/ school health services; promoção da saúde/ health promotion; planejamento em saúde/ health planning; pessoal de saúde/ health personnel; pessoal de educação/ educational personnel e estudantes/ students. Foi realizado o cruzamento dos termos de busca, descritores na LILACS e os MeSH terms no PUBMED, com o uso dos operadores booleanos AND e OR.

Os critérios de inclusão foram estudos publicados que estivessem disponíveis na íntegra, nos idiomas português, espanhol e inglês, que retratassem a temática sobre planejamento e desenvolvimento das ações de promoção da saúde no contexto escolar, incluindo publicações em que os participantes do estudo eram alunos, desde que descrevessem como as ações educativas foram planejadas e desenvolvidas pelos profissionais, no período de janeiro 2007 a dezembro 2019. Esse recorte temporal foi escolhido devido ao surgimento do Programa Saúde na Escola em 2007 (Farias et al., 2016). Os critérios de exclusão foram artigos que não reportavam a realidade brasileira, não correspondiam às questões de pesquisa, que se repetiram nas bases de dados, e que corresponderem a teses, dissertações e capítulos de livros.

O caminho percorrido está descrito pelo fluxograma apresentado na Figura 1, baseado no checklist PRISMA. 
Figura 1. Fluxograma de busca e seleção. Niterói, RJ, Brasil, 2020.

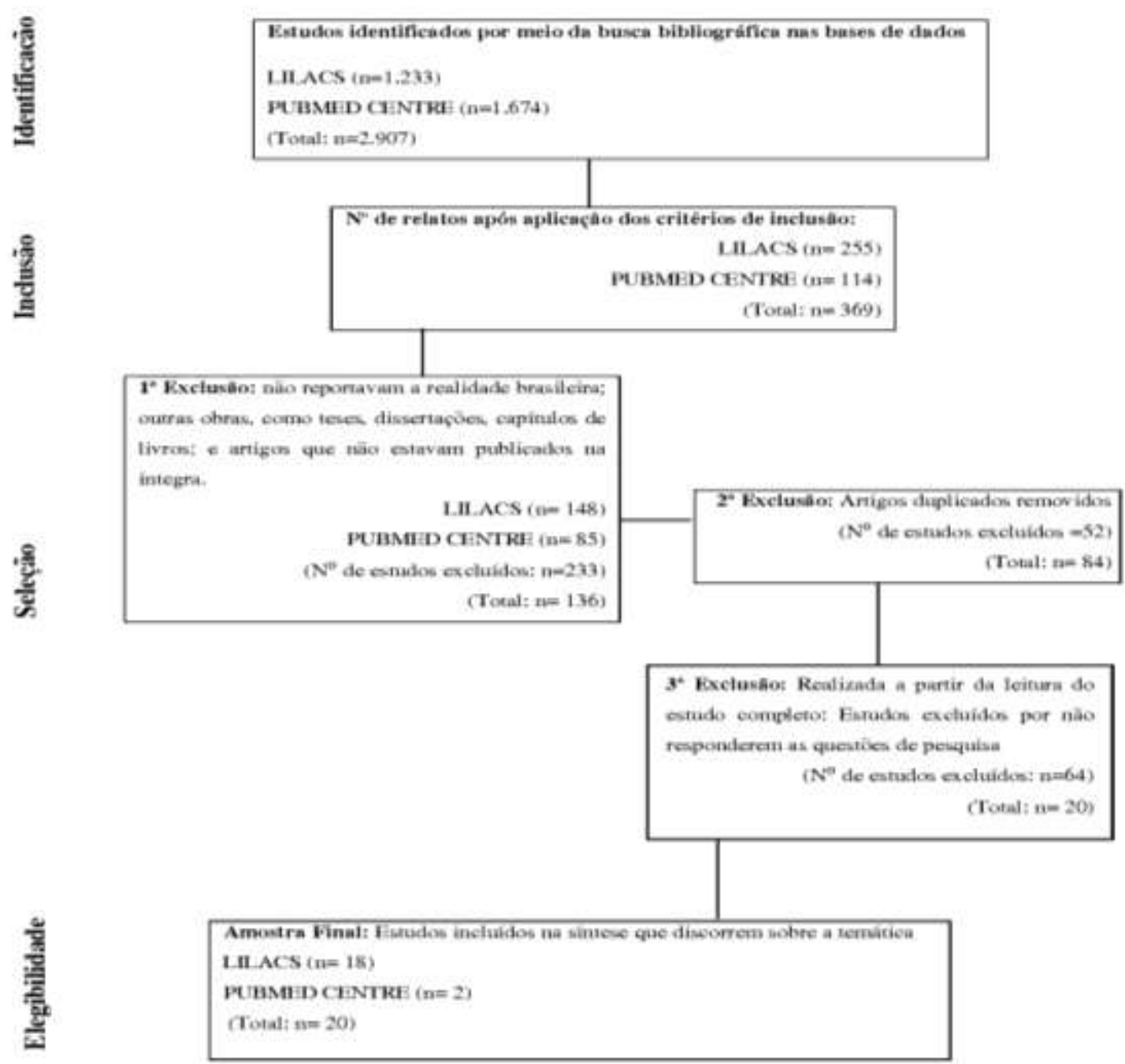

Fonte: Autores (2020).

Realizando uma análise da figura acima, observa-se que inicialmente 2.907 artigos foram identificados por meio da busca nas bases de dados. Desse total de artigos, foram eleitos 369 estudos após aplicação dos critérios de inclusão. A partir de então, foram aplicados os critérios de exclusão em 3 momentos. No primeiro momento, foram excluídos 233 estudos que não reportavam a realidade brasileira, obras como teses, dissertações, capítulos de livros e artigos que não estavam publicados na íntegra a partir da leitura dos títulos e/ou resumos das publicações, finalizando um número de 136 artigos. No segundo momento, foram descartados 52 artigos pela ocorrência de duplicidade, restando 84 estudos. No terceiro e último momento de exclusão, foi feita a leitura da publicação na íntegra para verificar a adequação do tema e questões de pesquisa, e 64 artigos foram excluídos. Dessa forma, o corpus de análise ficou caracterizado com 20 artigos científicos.

As informações obtidas foram sintetizadas e os resultados foram interpretados mediante análise descritiva, utilizando uma planilha Excel® que contemplou as seguintes informações: ano de publicação; título do artigo; base de dados; revista; região do Brasil; tipo de estudo; objetivos e síntese dos resultados. Os artigos foram numerados aleatoriamente para análise precedidos da letra $\mathrm{A}$, referente à palavra Artigo. Posteriormente, foram construídas as categorias analíticas de acordo com os objetivos da revisão e pergunta norteadora. 


\section{Resultados}

Com base nas informações extraídas dos 20 estudos selecionados, foi construído o quadro analítico, Quadro 1, segundo o número do artigo, título, ano, base de dados, periódico e região do Brasil.

Quadro 1. Distribuição dos estudos segundo número do artigo, título, ano, base de dados, periódico e região do Brasil. Niterói, RJ, Brasil, 2020.

\begin{tabular}{|c|c|c|c|c|c|}
\hline $\mathbf{N}^{\mathbf{o}}$ & Título & Ano & $\begin{array}{l}\text { Base de } \\
\text { Dados }\end{array}$ & Revista & $\begin{array}{l}\text { Região do Brasil/ } \\
\text { Estado }\end{array}$ \\
\hline A1 & $\begin{array}{l}\text { The school health program: teachers' } \\
\text { perceptions }\end{array}$ & 2015 & PUBMED & Invest Educ Enferm & Nordeste/ Ceará \\
\hline A2 & $\begin{array}{l}\text { Promoção de saúde nas escolas na perspectiva } \\
\text { de professores do ensino fundamental }\end{array}$ & 2013 & LILACS & Rev. Eletr. Enf. & Nordeste/ Paraíba \\
\hline A3 & $\begin{array}{l}\text { Percepções de profissionais de saúde da } \\
\text { família e de educação sobre a promoção da } \\
\text { saúde no ambiente escolar }\end{array}$ & 2013 & LILACS & Rev APS & $\begin{array}{l}\text { Sudeste/ Minas } \\
\text { Gerais }\end{array}$ \\
\hline A4 & $\begin{array}{l}\text { Educators' perspective on adolescente } \\
\text { sexuality: Possible education practices }\end{array}$ & 2014 & LILACS & REME & $\begin{array}{c}\text { Sul/ Santa } \\
\text { Catarina }\end{array}$ \\
\hline A5 & $\begin{array}{l}\text { Promoção da saúde no programa saúde na } \\
\text { escola e a inserção da enfermagem }\end{array}$ & 2014 & LILACS & REME & $\begin{array}{l}\text { Sudeste/ Minas } \\
\text { Gerais }\end{array}$ \\
\hline A6 & $\begin{array}{l}\text { Projetos e práticas em educação para a saúde } \\
\text { na educação física escolar: possibilidades! }\end{array}$ & 2015 & LILACS & Rev. Educ. Fís/UEM & $\begin{array}{l}\text { Sudeste/ Espirito } \\
\text { Santo }\end{array}$ \\
\hline A7 & $\begin{array}{l}\text { Análise da Intersetorialidade no Programa } \\
\text { Saúde na Escola }\end{array}$ & 2016 & LILACS & $\begin{array}{l}\text { Revista Brasileira de } \\
\text { Educação Médica }\end{array}$ & $\begin{array}{c}\text { Nordeste/ } \\
\text { Pernambuco }\end{array}$ \\
\hline A8 & Escolas promotoras de saúde & 2008 & LILACS & $\begin{array}{c}\text { Rev. Brasileira de } \\
\text { Crescimento e } \\
\text { Desenvolvimento Humano }\end{array}$ & $\begin{array}{l}\text { Sul/ Santa } \\
\text { Catarina }\end{array}$ \\
\hline A9 & $\begin{array}{l}\text { Orientação sexual: conhecimentos e } \\
\text { necessidades de professores de um colégio } \\
\text { público de Goiânia-GO }\end{array}$ & 2008 & LILACS & $\begin{array}{l}\text { Rev. Eletrônica de } \\
\text { Enfermagem }\end{array}$ & $\begin{array}{l}\text { Centro-Oeste/ } \\
\text { Goiás }\end{array}$ \\
\hline A10 & A promoção da saúde na educação infantil & 2008 & LILACS & $\begin{array}{l}\text { Rev. Interface: } \\
\text { Comunicação, } \\
\text { Saúde, Educação }\end{array}$ & Nordeste/ Ceará \\
\hline A11 & $\begin{array}{l}\text { Educative practices and atitudes within the } \\
\text { pre-school environment: evaluating the } \\
\text { education professionals }\end{array}$ & 2008 & LILACS & Brazilian Oral Research & $\begin{array}{l}\text { Sudeste/ Rio de } \\
\text { Janeiro }\end{array}$ \\
\hline A12 & $\begin{array}{l}\text { Percepção dos educadores e coordenadores de } \\
\text { uma creche sobre processo educativo em saúde } \\
\text { desenvolvido com abordagem } \\
\text { multiprofissional }\end{array}$ & 2009 & LILACS & $\begin{array}{l}\text { Rev. de Atenção Primária } \\
\text { à Saúde }\end{array}$ & $\begin{array}{l}\text { Sudeste/ São } \\
\quad \text { Paulo }\end{array}$ \\
\hline A13 & A abordagem do álcool no contexto do ensino & 2010 & LILACS & Rev. Latino-americana de & Sudeste/ Rio de \\
\hline
\end{tabular}




\begin{tabular}{|c|c|c|c|c|c|}
\hline & $\begin{array}{l}\text { fundamental: a reconstrução socioimaginária } \\
\text { dos docentes }\end{array}$ & & & Enfermagem & Janeiro \\
\hline A14 & $\begin{array}{l}\text { Hábitos alimentares e prática de atividade } \\
\text { física em escolares: relato de uma experiência } \\
\text { de educação em saúde }\end{array}$ & 2011 & LILACS & $\begin{array}{l}\text { Rev. de Atenção Primária } \\
\text { à Saúde }\end{array}$ & $\begin{array}{l}\text { Sudeste/ Rio de } \\
\text { Janeiro }\end{array}$ \\
\hline A15 & $\begin{array}{l}\text { Oficinas educativas como estratégia de } \\
\text { promoção da saúde auditiva do adolescente: } \\
\text { estudo exploratório }\end{array}$ & 2013 & LILACS & $\begin{array}{c}\text { Audiology: } \\
\text { Communication Research }\end{array}$ & Sul/ Paraná \\
\hline A16 & $\begin{array}{l}\text { Intervenção educativa sobre violência com } \\
\text { adolescentes: possibilidade para a enfermagem } \\
\text { no contexto escolar }\end{array}$ & 2014 & LILACS & $\begin{array}{c}\text { Escola Anna Nery Rev. De } \\
\text { Enfermagem }\end{array}$ & $\begin{array}{c}\text { Nordeste/ } \\
\text { Pernambuco }\end{array}$ \\
\hline A17 & $\begin{array}{l}\text { O enfermeiro e a temática da hanseníase no } \\
\text { contexto escolar: relato de experiência }\end{array}$ & 2015 & LILACS & $\begin{array}{l}\text { Rev. de Pesquisa: Cuidado } \\
\text { é Fundamental }\end{array}$ & $\begin{array}{l}\text { Nordeste/ Rio } \\
\text { Grande do Norte }\end{array}$ \\
\hline A18 & $\begin{array}{l}\text { Facilidades e dificuldades na implantação do } \\
\text { Programa Saúde na Escola em um município } \\
\text { do nordeste do Brasil }\end{array}$ & 2018 & LILACS & Resvista Cuidarte & $\begin{array}{l}\text { Nordeste/ Rio } \\
\text { Grande do Norte }\end{array}$ \\
\hline A19 & $\begin{array}{l}\text { A percepção de educadores sobre a escola } \\
\text { promotora de saúde: um estudo de caso }\end{array}$ & 2007 & LILACS & $\begin{array}{l}\text { RevBras Crescimento } \\
\text { Desenvolv Hum. }\end{array}$ & $\begin{array}{l}\text { Sudeste/ São } \\
\text { Paulo }\end{array}$ \\
\hline A20 & $\begin{array}{l}\text { School health promotion and use of drugs } \\
\text { among students in Southern Brazil }\end{array}$ & 2018 & PUBMED & Revista de Saúde Pública & $\begin{array}{l}\text { Sul/ Rio Grande } \\
\text { do Sul }\end{array}$ \\
\hline
\end{tabular}

Fonte: Autores (2020).

Conforme descrito no quadro acima a partir dos 20 artigos científicos selecionados como corpus de análise, 18 (90\%) são provenientes da LILACS, dois (10\%) do PubMed. Quanto ao ano de publicação, compreendidos entre 2007 a 2019, em 2007 foi encontrado um (5\%) artigo; em 2008, quatro (20\%) artigos; em 2009, um (5\%) artigo; em 2010, um (5\%) artigo; em 2011, um (5\%) artigo; em 2013, três (15\%) artigos; em 2014, três (15\%) artigos; em 2015, três (15\%) artigos; em 2016, um (5\%) artigo e em 2018, dois (10\%) artigos. Não foi encontrado nenhum artigo em 2012, 2017 e 2019.

Analisando as publicações por regiões do Brasil, percebe-se que oito (40\%) artigos são provenientes da região Sudeste, sete $(35 \%)$ da região Nordeste, quatro $(20 \%)$ da região Sul e uma $(5 \%)$ da região Centro-oeste. Não foram encontradas publicações provenientes da região Norte do Brasil.

Os artigos também foram avaliados quanto ao tipo de estudo, os objetivos e a síntese dos resultados conforme descritos no Quadro 2. 
Quadro 2. Distribuição dos estudos segundo tipo de estudo, objetivos e síntese dos resultados Niterói, RJ, Brasil, 2020.

\begin{tabular}{|c|c|c|c|}
\hline $\mathbf{N}^{\circ}$ & $\begin{array}{l}\text { Tipo de } \\
\text { estudo }\end{array}$ & Objetivos & Síntese dos Resultados \\
\hline A1 & $\begin{array}{l}\text { Descritivo } \\
\qquad \text { de } \\
\text { abordagem } \\
\text { qualitativa }\end{array}$ & $\begin{array}{l}\text { Entender a percepção dos professores } \\
\text { sobre o programa de saúde escolar e } \\
\text { sua relação com as atividades de } \\
\text { educação em saúde desenvolvidas na } \\
\text { escola. }\end{array}$ & $\begin{array}{l}\text { Os professores têm uma visão assistencialista do PSE, } \\
\text { não referem integração entre os professores e } \\
\text { profissionais da saúde com conteúdo não relacionado ao } \\
\text { interesse dos adolescentes. Ações educativas em saúde na } \\
\text { escola se resumem a avaliações clínicas, } \\
\text { descontextualizadas, com foco na prevenção de algumas } \\
\text { doenças. Os participantes relatam ações isoladas e } \\
\text { executadas por diferentes agentes. Há uma necessidade } \\
\text { de relação mais próxima, a fim de otimizar esforços para } \\
\text { promover a saúde escolar. }\end{array}$ \\
\hline A2 & $\begin{array}{l}\text { Descritivo } \\
\text { de } \\
\text { abordagem } \\
\text { qualitativa }\end{array}$ & $\begin{array}{l}\text { Caracterizar como as atividades de } \\
\text { promoção da saúde são desenvolvidas } \\
\text { pelos professores do ensino } \\
\text { fundamental das escolas públicas de } \\
\text { ensino fundamental de um município } \\
\text { da Paraíba }\end{array}$ & $\begin{array}{l}\text { Ações de educação em saúde são integradas às datas } \\
\text { comemorativas e campanhas, com iniciativa apenas do } \\
\text { setor saúde, aspecto que incentiva ações pontuais, } \\
\text { descontextualizadas e com acentuado aspecto normativo, } \\
\text { prescritivo e de fundamentação biológica. Desconsidera- } \\
\text { se o planejamento coletivo e a avaliação das ações } \\
\text { executadas. }\end{array}$ \\
\hline A3 & $\begin{array}{l}\text { Exploratóri } \\
\text { o de } \\
\text { abordagem } \\
\text { qualitativa }\end{array}$ & $\begin{array}{l}\text { Investigar a percepção de } \\
\text { profissionais de saúde e educação } \\
\text { sobre a importância da promoção da } \\
\text { saúde realizada pela Estratégia Saúde } \\
\text { da Família, em escolas públicas do } \\
\text { município de Juiz de Fora/MG }\end{array}$ & $\begin{array}{l}\text { Os entrevistados consideraram importante as ações com } \\
\text { foco no desenvolvimento de hábitos saudáveis e } \\
\text { prevenção de doenças. As ações realizadas muitas vezes } \\
\text { são palestras, ora são teatros e orientações gerais. } \\
\text { Contudo, observou-se que não existe uma regularidade de } \\
\text { oferta e planejamento. }\end{array}$ \\
\hline A4 & $\begin{array}{l}\text { Descritivo } \\
\text { com } \\
\text { abordagem } \\
\text { qualitativa }\end{array}$ & $\begin{array}{l}\text { Conhecer a concepção dos } \\
\text { educadores sobre adolescência e } \\
\text { sexualidade e evidenciar estratégias } \\
\text { utilizadas quando discutem o tema } \\
\text { sexualidade. }\end{array}$ & $\begin{array}{l}\text { Os professores afirmam que a educação sexual é uma } \\
\text { área complexa e de difícil abordagem. Mostram-se } \\
\text { temerosos e pouco preparados para abordar o assunto. } \\
\text { Apresentam visões diferentes sobre o processo de } \\
\text { adolescer e da sexualidade. Alguns utilizam metodologias } \\
\text { de ensino tradicionais e outros adotam estratégias } \\
\text { participativas, valorizando o diálogo. Concluiu-se que a } \\
\text { discussão sobre sexualidade na adolescência, no âmbito } \\
\text { escolar, ainda é incipiente, centrada em visões } \\
\text { tradicionais e discutida por áreas do conhecimento que } \\
\text { estudam as questões biológicas. Sendo assim, observa-se } \\
\text { dificuldade de incluí-lo como um tema transversal. }\end{array}$ \\
\hline A5 & $\begin{array}{l}\text { Estudo de } \\
\text { caso de } \\
\text { abordagem } \\
\text { qualitativa }\end{array}$ & $\begin{array}{l}\text { Analisar o Programa Saúde na Escola } \\
\text { (PSE) em um município do estado de } \\
\text { Minas Gerais, identificando sua } \\
\text { organização, a atuação dos }\end{array}$ & $\begin{array}{l}\text { Os resultados indicam que o PSE se encontra em } \\
\text { processo de consolidação, com ações que variam desde } \\
\text { avaliação de risco e mudança de comportamento até } \\
\text { aquelas que reforçam a escola como espaço potencial }\end{array}$ \\
\hline
\end{tabular}




\begin{tabular}{|c|c|c|c|}
\hline & & $\begin{array}{l}\text { profissionais de enfermagem e sua } \\
\text { inserção no campo da promoção da } \\
\text { saúde }\end{array}$ & $\begin{array}{l}\text { para a promoção da saúde. Notou-se desafios como a } \\
\text { transferência de responsabilidade para a escola na } \\
\text { formação de hábitos, comportamentos e valores como se } \\
\text { fosse esse o único ou o principal lugar no } \\
\text { desenvolvimento da cidadania e no cuidado à saúde. A } \\
\text { relação entre saúde e educação apresenta-se como outro } \\
\text { desafio a ser superado. Destaca-se o papel dos } \\
\text { enfermeiros nas ações educativas em saúde com potencial } \\
\text { de responder às questões de saúde escolar. Concluiu-se } \\
\text { que é preciso avançar em inovações tecnológicas } \\
\text { educacionais no âmbito das práticas do PSE que } \\
\text { ressignifiquem a escola como cenário da promoção da } \\
\text { saúde, em uma visão que considere o potencial de } \\
\text { produção de cidadania e mudanças nesse espaço. }\end{array}$ \\
\hline A6 & $\begin{array}{l}\text { Pesquisa- } \\
\text { ação de } \\
\text { abordagem } \\
\text { qualitativa }\end{array}$ & $\begin{array}{l}\text { Investigar como o tema da saúde é } \\
\text { e/ou pode ser abordado nas práticas } \\
\text { pedagógicas de Educação Física (EF) } \\
\text { escolar e suas contribuições no } \\
\text { desenvolvimento da educação para a } \\
\text { saúde. }\end{array}$ & $\begin{array}{l}\text { Foram desenvolvidos cinco projetos que tematizaram a } \\
\text { saúde. Buscou-se trabalhar com um conceito ampliado de } \\
\text { saúde, superando a concepção clássica de ausência de } \\
\text { doença, orientada pela biologia. Compreende-se que a } \\
\text { saúde é um tema de responsabilidade de toda a escola e } \\
\text { não uma exclusividade da Educação Física. Para essa } \\
\text { disciplina, a saúde é uma questão pedagógica, com } \\
\text { intervenções específicas, ligadas à cultura corporal de } \\
\text { movimento, podendo construir espaços de } \\
\text { relacionamentos mais saudáveis. }\end{array}$ \\
\hline A7 & $\begin{array}{l}\text { Estudo de } \\
\text { caso de } \\
\text { abordagem } \\
\text { qualitativa }\end{array}$ & $\begin{array}{l}\text { Conhecer e analisar processo da } \\
\text { intersetorialidade no PSE em um } \\
\text { município da Região metropolitana } \\
\text { de Pernambuco }\end{array}$ & $\begin{array}{l}\text { A pesquisa revelou que o maior dilema do PSE é operar } \\
\text { uma política intersetorial, explicitada num ambiente com } \\
\text { atores que possuem agendas setoriais previamente } \\
\text { montadas e sem espaço suficiente tal fato leva à } \\
\text { dificuldade de conciliar os tempos institucionais dos } \\
\text { vários setores, o comprometimento e envolvimento } \\
\text { setorial, impedindo a sustentabilidade das ações. } \\
\text { Mudanças estão sendo implementadas, mas o que se } \\
\text { observa é a escassez de capacitação e educação } \\
\text { permanente, além da inexistência de protocolos que } \\
\text { norteiem o desenvolvimento de ações intersetoriais. Foi } \\
\text { identificado o conceito do PSE alinhado ao conceito } \\
\text { governamental, a importância do PSE, baixa } \\
\text { credibilidade do PSE, baixa credibilidade da gestão } \\
\text { municipal, deficiência de capacitações. Além do conceito } \\
\text { de intersetorialidade restrito, intersetorialidade } \\
\text { saúde/educação no PSE, conflito de interesses entre os } \\
\text { setores saúde e educação, deficiência na comunicação e } \\
\text { poucos interlocutores. }\end{array}$ \\
\hline
\end{tabular}




\begin{tabular}{|c|c|c|c|}
\hline A8 & $\begin{array}{l}\text { Descritivo } \\
\text { com } \\
\text { abordagem } \\
\text { qualitativa }\end{array}$ & $\begin{array}{l}\text { Propor um processo de educação } \\
\text { continuada, para que as escolas se } \\
\text { tornem promotoras de saúde, por } \\
\text { meio da identificação da percepção } \\
\text { dos professores em relação aos temas: } \\
\text { saúde, promoção e educação em } \\
\text { saúde e a necessidade de capacitação } \\
\text { nos mesmos temas. }\end{array}$ & $\begin{array}{l}\text { O conceito de saúde dos professores limita-se ao bem } \\
\text { estar físico, focado no modelo biomédico. Não } \\
\text { relacionam saúde com qualidade de vida. O conceito de } \\
\text { educação em saúde é a transmissão de informações sobre } \\
\text { cuidados de higiene. Dentro do ambiente escolar são } \\
\text { realizadas ações com ênfase na transmissão de conceitos } \\
\text { relacionados à higiene corporal. A identificação dos } \\
\text { problemas de saúde dos escolares somente era realizada } \\
\text { quando os alunos manifestavam sintomas de doenças. }\end{array}$ \\
\hline A9 & $\begin{array}{l}\text { Descritivo- } \\
\text { exploratória } \\
\text { de } \\
\text { abordagem } \\
\text { quantitativa }\end{array}$ & $\begin{array}{l}\text { Verificar o conhecimento dos } \\
\text { professores sobre educação sexual e } \\
\text { prevenção de DST, bem como } \\
\text { identificar o nível de dificuldade dos } \\
\text { mesmos ao lidar com esta temática no } \\
\text { ambiente escolar. }\end{array}$ & $\begin{array}{l}\text { Os profissionais de educação possuem dificuldades para } \\
\text { trabalhar a temática educação sexual no ambiente escolar. } \\
\text { As respostas sinalizam um despreparo técnico, com falta } \\
\text { de informações recentes sobre a temática, vergonha ou o } \\
\text { tabu os impedem de falar sobre o tema e ainda a falta de } \\
\text { recursos didáticos disponíveis na escola. A maioria } \\
\text { encontrou dificuldades de abordar o tema pelo } \\
\text { desconhecimento sobre o papel da escola no } \\
\text { desenvolvimento da orientação sexual, bem como a não } \\
\text { distinção entre orientação sexual, educação sexual e o } \\
\text { papel da família. }\end{array}$ \\
\hline A10 & $\begin{array}{l}\text { Descritivo } \\
\text { com } \\
\text { abordagem } \\
\text { qualitativa }\end{array}$ & $\begin{array}{l}\text { Descrever o trabalho de promoção da } \\
\text { saúde desenvolvido por uma escola } \\
\text { de educação infantil que incorpora } \\
\text { princípios de promoção da saúde em } \\
\text { sua prática pedagógica, investigando } \\
\text { seis sujeitos que vivenciaram o } \\
\text { processo }\end{array}$ & $\begin{array}{l}\text { O cuidado foi considerado, pela equipe pedagógica, como } \\
\text { elemento presente no trabalho de promoção da saúde na } \\
\text { educação infantil. A escola utiliza a Pedagogia de } \\
\text { Projetos, com temas sobre alimentação saudável, higiene } \\
\text { na escola, como referencial de proposta metodológica. }\end{array}$ \\
\hline A11 & $\begin{array}{l}\text { Descritivo } \\
\text { com } \\
\text { abordagem } \\
\text { quanti- } \\
\text { qualitativa }\end{array}$ & $\begin{array}{l}\text { Avaliar as práticas e atitudes em } \\
\text { relação à atenção à saúde bucal de } \\
245 \text { profissionais da educação que } \\
\text { trabalham em } 24 \text { pré-escolas } \\
\text { municipais públicas em Niterói }\end{array}$ & $\begin{array}{l}\text { A maioria dos profissionais de educação mostraram } \\
\text { atitudes positivas em relação à atenção à saúde bucal } \\
\text { preventiva, respondendo positivamente ao próprio } \\
\text { envolvimento em programas de educação em saúde que } \\
\text { visam promover hábitos orais saudáveis entre escolares e } \\
\text { em outros estudos. Os profissionais de educação também } \\
\text { acreditaram que estabelecer um intercâmbio com os } \\
\text { dentistas é importante porque esses profissionais são } \\
\text { reconhecidos como parceiros ideais para desenvolver } \\
\text { programas de educação em saúde, bem como as seguintes } \\
\text { atividades integradas: projetos pedagógicos, debates, } \\
\text { discussões em grupo, palestras, oficinas, elaboração de } \\
\text { materiais educativos e conferências. }\end{array}$ \\
\hline A12 & $\begin{array}{l}\text { Descritivo- } \\
\text { exploratória } \\
\text { de }\end{array}$ & $\begin{array}{l}\text { Verificar a percepção dos educadores } \\
\text { e coordenadores do Centro de } \\
\text { Educação Infantil Parque Santa Rita }\end{array}$ & $\begin{array}{l}\text { Para elaboração de estratégias pedagógicas, considerou- } \\
\text { se a realidade local, levando-se em conta os aspectos } \\
\text { socioeconômicos e culturais. O trabalho educativo pode }\end{array}$ \\
\hline
\end{tabular}




\begin{tabular}{|c|c|c|c|}
\hline & $\begin{array}{l}\text { abordagem } \\
\text { qualitativa }\end{array}$ & $\begin{array}{l}\text { sobre o processo educativo } \\
\text { desenvolvido por meio da abordagem } \\
\text { multiprofissional, considerando a } \\
\text { proposta de atuação intersetorial } \\
\text { (saúde - educação) e as relações entre } \\
\text { família - escola - comunidade dentro } \\
\text { da lógica ampliada de atuação do } \\
\text { Programa Saúde da Família }\end{array}$ & $\begin{array}{l}\text { criar condições para que os partícipes construíssem um } \\
\text { novo conhecimento, reconstruindo cenas num processo } \\
\text { contínuo de acesso à materiais e informações. A equipe } \\
\text { buscou dialogar com os profissionais. E, no trabalho com } \\
\text { as crianças, tentou identificar seus interesses e } \\
\text { expectativas, para que o processo de troca fosse } \\
\text { enriquecedor. }\end{array}$ \\
\hline A13 & $\begin{array}{l}\text { Descritivo } \\
\text { com } \\
\text { abordagem } \\
\text { qualitativa }\end{array}$ & $\begin{array}{l}\text { a) Identificar as estratégias } \\
\text { pedagógicas desenvolvidas pelos } \\
\text { professores do ensino fundamental, } \\
\text { na abordagem sobre o álcool junto } \\
\text { aos adolescentes, } \\
\text { b) analisar as atitudes, crenças, } \\
\text { valores e práticas dos professores do } \\
\text { ensino fundamental em relação ao } \\
\text { álcool, } \\
\text { c) discutir as repercussões das } \\
\text { atitudes, crenças, valores e práticas } \\
\text { dos professores sobre álcool, na } \\
\text { interlocução com os alunos e na } \\
\text { implementação das estratégias } \\
\text { suprarreferidas }\end{array}$ & $\begin{array}{l}\text { Nas representações dos professores, o foco das principais } \\
\text { políticas públicas sobre o uso ou do abuso do álcool é } \\
\text { direcionado para o adolescente. Contudo, o docente } \\
\text { necessita abordar o assunto em seu dia a dia profissional, } \\
\text { independente de seus conhecimentos. Fato que gera } \\
\text { cotidiano tenso em que oportunidades de educação em } \\
\text { saúde são perdidas como consequência das dificuldades } \\
\text { de compreensão do assunto. Sugeriu-se a participação do } \\
\text { enfermeiro como educador de saúde, no processo de } \\
\text { transformação da escola, com aparato técnico-científico e } \\
\text { legal para desenvolver programas, visando a promoção da } \\
\text { saúde. Quanto as estratégias pedagógicas desenvolvidas, } \\
\text { grande parte dos depoentes afirmaram utilizar dinâmicas } \\
\text { de grupo para facilitar a discussão em sala de aula, leitura } \\
\text { de textos atuais, dramatização, redação, vídeos e, } \\
\text { também, aulas programadas dentro dos conteúdos } \\
\text { previstos para determinadas disciplinas como ciências e } \\
\text { artes. }\end{array}$ \\
\hline A14 & $\begin{array}{l}\text { Descritivo } \\
\text { com } \\
\text { abordagem } \\
\text { quantitativa }\end{array}$ & $\begin{array}{l}\text { Conhecer os hábitos alimentares e } \\
\text { estilo de vida dos alunos de uma } \\
\text { escola pública da cidade do Rio de } \\
\text { Janeiro, visando à promoção de ações } \\
\text { educativas voltadas para as } \\
\text { necessidades de saúde dos alunos } \\
\text { desta escola }\end{array}$ & $\begin{array}{l}\text { As atividades foram desenvolvidas com base em técnicas } \\
\text { de dinâmica de grupo, visando não só valorizar a } \\
\text { participação do grupo como também identificar o } \\
\text { conhecimento dos estudantes sobre o tema, estimular seu } \\
\text { interesse por ele, conhecer suas perspectivas e as } \\
\text { possibilidades de adoção, pelos alunos, das competências } \\
\text { trabalhadas. }\end{array}$ \\
\hline A15 & $\begin{array}{l}\text { Pesquisa- } \\
\text { ação de } \\
\text { abordagem } \\
\text { qualitativa }\end{array}$ & $\begin{array}{l}\text { Desenvolver e avaliar oficinas } \\
\text { educativas sobre saúde auditiva e } \\
\text { exposição a ruídos de adolescentes } \\
\text { escolares da rede pública de ensino } \\
\text { médio }\end{array}$ & $\begin{array}{l}\text { O trabalho em grupo, na forma de oficinas ou outros, } \\
\text { possibilitou a quebra da tradicional relação vertical que } \\
\text { existe entre o profissional da saúde e o sujeito da sua } \\
\text { ação. Utilizou-se uma estratégia facilitadora da expressão } \\
\text { individual e coletiva das necessidades, expectativas e } \\
\text { circunstâncias de vida que influenciam a saúde. Foi } \\
\text { destacada a importância das ações educativas baseadas no } \\
\text { comportamento relacionado às atitudes e aos hábitos } \\
\text { auditivos de crianças e adolescentes, permitindo a } \\
\text { construção da consciência coletiva e o encontro da }\end{array}$ \\
\hline
\end{tabular}




\begin{tabular}{|c|c|c|c|}
\hline & & & reflexão com a ação. \\
\hline A16 & $\begin{array}{l}\text { Pesquisa- } \\
\text { ação de } \\
\text { abordagem } \\
\text { qualitativa }\end{array}$ & $\begin{array}{l}\text { Realizar uma intervenção educativa } \\
\text { com adolescentes sobre a violência } \\
\text { no contexto escolar, utilizando a } \\
\text { metodologia de Círculos de Cultura }\end{array}$ & $\begin{array}{l}\text { Refletiu a necessidade de um trabalho valorativo que dê } \\
\text { aos adolescentes o poder da fala, da protagoniza-ação, da } \\
\text { expressão artística, como instrumento singular para uma } \\
\text { ação educativa comprometida com a consciência crítica } \\
\text { da realidade e o empoderamento dos atores envolvidos. A } \\
\text { escola foi eleita como ambiente propício para ações de } \\
\text { promoção à saúde, podendo constituir campo profícuo } \\
\text { para construção de propostas de prevenção da violência. }\end{array}$ \\
\hline A17 & $\begin{array}{c}\text { Relato de } \\
\text { Experiência } \\
\text { com } \\
\text { abordagem } \\
\text { qualitativa }\end{array}$ & $\begin{array}{l}\text { Avaliar o conhecimento de escolares } \\
\text { acerca da hanseníase e implementar } \\
\text { ações de educação em saúde sobre } \\
\text { esta temática }\end{array}$ & $\begin{array}{l}\text { Foi sugerida a identificação } \\
\text { conhecimentos prévios daqueles com os quais fosse } \\
\text { realizada a ação de educação em saúde. Ressaltado a } \\
\text { importância das ações serem operacionalizadas de modo } \\
\text { horizontalizado, com base na escuta ativa e no } \\
\text { relacionamento humanizado, superando a mera } \\
\text { transmissão de conteúdos. }\end{array}$ \\
\hline A18 & $\begin{array}{l}\text { Descritivo, } \\
\text { abordagem } \\
\text { quantitativa }\end{array}$ & $\begin{array}{lrrr}\text { Identificar as facilidades } & \text { e } \\
\text { dificuldades na implantação } & \text { do } \\
\text { Programa Saúde na Escola } & \text { em } \\
\text { município do nordeste brasileiro }\end{array}$ & $\begin{array}{l}\text { A satisfação dos profissionais e a articulação entre os } \\
\text { setores saúde e educação foram elementos facilitadores } \\
\text { na implantação do Programa Saúde na Escola. No } \\
\text { entanto, insuficiência de recursos materiais e financeiros } \\
\text { e excesso de atribuições no processo de trabalho foram } \\
\text { exemplos de fatores que comprometem sua implantação. }\end{array}$ \\
\hline A19 & $\begin{array}{l}\text { Estudo de } \\
\text { caso com } \\
\text { abordagem } \\
\text { qualitativa }\end{array}$ & $\begin{array}{l}\text { Identificar o entendimento e a } \\
\text { percepção que educadores de uma } \\
\text { escola pública paulistana têm quanto } \\
\text { às temáticas educação em saúde e } \\
\text { promoção da saúde na escola e } \\
\text { quanto às práticas desenvolvidas no } \\
\text { ambiente escolar para promover } \\
\text { saúde }\end{array}$ & $\begin{array}{l}\text { Identificou-se que ações educacionais são bastante } \\
\text { heterogêneas, mas há predominância de uma concepção } \\
\text { especialista, ou seja, o professor de Ciências foi } \\
\text { considerado o mais habilitado a desenvolver práticas de } \\
\text { educação em saúde. Também se observou a tendência à } \\
\text { visão assistencialista, que se baseia na preocupação com } \\
\text { o cuidado pontual, sem, muitas vezes, considerar } \\
\text { condições histórico-sociais da comunidade escolar. } \\
\text { Quanto ao desenvolvimento de ações relacionadas à } \\
\text { promoção da saúde, a maioria dos professores exclui-se } \\
\text { do processo de planejamento e execução e atribuiu esse } \\
\text { papel ao diretor e ao coordenador pedagógico. Assim, sua } \\
\text { atuação foi marcada pela realização de tarefas, definidas } \\
\text { pelos que ocupam outras funções, caracterizando um } \\
\text { distanciamento entre as atividades de planejamento e as } \\
\text { de ação. }\end{array}$ \\
\hline A 20 & $\begin{array}{l}\text { Estudo } \\
\text { descritivo- } \\
\text { exploratório } \\
\text { com }\end{array}$ & $\begin{array}{l}\text { Analisar a relação entre condições de } \\
\text { promoção de saúde nas escolas e o } \\
\text { consumo de álcool e outras drogas } \\
\text { pelos escolares. }\end{array}$ & $\begin{array}{l}\text { O estudo demonstrou que melhores condições de } \\
\text { promoção de saúde no ambiente escolar podem contribuir } \\
\text { para menores prevalências do uso de álcool e tabaco. } \\
\text { Ressaltou que o PSE no Brasil, prevê articulação entre a }\end{array}$ \\
\hline
\end{tabular}




\begin{tabular}{|c|c|c|l|}
\hline $\begin{array}{c}\text { abordagem } \\
\text { quantitativa }\end{array}$ & $\begin{array}{l}\text { escola e a comunidade, por meio da Estratégia de Saúde } \\
\text { da Família, existindo o desafio para as equipes de ambas } \\
\text { as instituições de estreitarem laços e firmarem parcerias } \\
\text { com ações colaborativas nas escolas. }\end{array}$ \\
\hline
\end{tabular}

Fonte: Autores (2020).

Nota-se, a partir do quadro acima, que houve uma predominância de estudos qualitativos 15 (75\%) artigos, em relação aos estudos quantitativos quatro (20\%) artigos e quanti-qualitativos um (5\%) artigo. Quanto ao tipo de estudo, a maioria é descritivo nove (45\%) artigos, enquanto, três (15\%) pesquisa-ação, três (15\%) estudo de caso, três (15\%) descritivoexploratório, um (5\%) exploratório e um (5\%) relato de experiência.

Quanto ao nível de evidencia os estudos, estes foram analisados pela classificação hierárquica segundo a abordagem metodológica adotada, distribuídos em sete níveis: Nível I (revisões sistemáticas ou metanálises); Nível II (os ensaios clínicos randomizados controlados); Nível III (os ensaios clínicos sem randomização); Nível IV (estudos de coorte ou caso-controle); Nível V (revisões sistemáticas de estudos descritivos e qualitativos); Nível VI (estudos descritivos ou qualitativos); Nível VII (opiniões de autoridades e/ou relatórios de comitês de especialidades) (Galvão, 2006). Dessa forma, dos 20 estudos, todos (100\%) se enquadram no nível de evidência VI.

Após análise dos artigos, foram criadas três categorias: As diferentes visões de promoção da Saúde; Planejamento das ações de promoção da saúde; e Desenvolvimento das ações promoção da saúde nas escolas. O agrupamento dos artigos em categorias analíticas encontra-se caracterizado no Quadro 3.

Quadro 3. Categorias Analíticas. Niterói, RJ, Brasil, 2020.

\begin{tabular}{|l|c|}
\hline \multicolumn{1}{|c|}{ Categoria 1: As diferentes visões de promoção da Saúde } & Estudos \\
\hline - Relacionado à prevenção de doenças com foco no modelo biológico de saúde & $\mathrm{A} 1, \mathrm{~A} 3, \mathrm{~A} 6, \mathrm{~A} 8, \mathrm{~A} 13, \mathrm{~A} 19$ \\
\hline - Relacionado à qualidade de vida e educação em saúde & $\mathrm{A} 2, \mathrm{~A} 6, \mathrm{~A} 10, \mathrm{~A} 17$ \\
\hline \multicolumn{1}{|c|}{ Categoria 2: Planejamento das ações de promoção da saúde } & Estudos \\
\hline - Falta de integração entre saúde X educação & $\mathrm{A} 1, \mathrm{~A} 2, \mathrm{~A} 3, \mathrm{~A} 5, \mathrm{~A} 7, \mathrm{~A} 9, \mathrm{~A} 13$, \\
\hline - Falta de regularidade ou inexistência de planejamento & $\mathrm{A} 18, \mathrm{~A} 19, \mathrm{~A} 20$ \\
\hline - Não identificação prévia das necessidades dos educandos & $\mathrm{A} 1, \mathrm{~A} 2, \mathrm{~A} 3, \mathrm{~A} 4, \mathrm{~A} 8, \mathrm{~A} 19$ \\
\hline - Identificação das necessidades e interesses previamente & $\mathrm{A} 1, \mathrm{~A} 8, \mathrm{~A} 19$ \\
\hline - Necessidade de Inovações tecnológicas & $\mathrm{A} 12, \mathrm{~A} 17$ \\
\hline \multicolumn{1}{|c|}{ Categoria 3: Desenvolvimento das ações promoção da saúde nas escolas } & $\mathrm{A} 4, \mathrm{~A} 5, \mathrm{~A} 13$ \\
\hline $\begin{array}{l}\text { - Baseado no modelo biomédico: ações tradicionais, pontuais, higienistas, avaliações } \\
\text { clínicas e palestras }\end{array}$ & $\mathrm{Estudos}$ \\
\hline $\begin{array}{l}\text { - Baseado no modelo dialógico: dinâmicas de grupo, lúdico, teatro, discussão textuais, } \\
\text { debates, roda de conversa, mural, música e oficinas. }\end{array}$ & $\mathrm{A} 9, \mathrm{~A} 13, \mathrm{~A} 14, \mathrm{~A} 6, \mathrm{~A} 19$ \\
\hline - Baseado no modelo biomédico e dialógico & $\mathrm{A} 3, \mathrm{~A} 4, \mathrm{~A} 9, \mathrm{~A} 10, \mathrm{~A} 11$ \\
\hline
\end{tabular}

Fonte: Autores (2020).

A apresentação dos achados dos artigos inseridos em cada categoria analítica, de acordo com o Quadro 3, serão discutidos a seguir nas categorias apresentadas na discussão deste estudo. 


\section{Discussão}

Após leitura do corpus dos artigos e análise de seus resultados ficou evidenciado que é a partir da visão de promoção da saúde dos profissionais de saúde e educação que se originam as ações de promoção da saúde no ambiente escolar. Assim, o entendimento de promoção da saúde implica mudanças profundas na forma de articular, planejar e utilizar o conhecimento na formulação e operacionalização das ações educativas em saúde na escola.

\section{As diferentes visões de promoção da Saúde}

Foram identificados diferentes tipos de compreensão do significado de promoção da saúde dentre os profissionais de saúde e educação, tal como relacionado à prevenção de doenças com foco no modelo biológico de saúde, assim como à qualidade de vida e educação em saúde.

Dos artigos analisados, seis (30\%) estudos (Leite, Machado, Vieira, Marinho \& Monteiro, 2015; Cardoso, Reis \& Iervolino, 2008; Oliveira, Martins \& Bracht, 2015; Faria, Aguiar, Moura \& Souza, 2013; Felipe \& Gomes, 2010; Santos \& Bógus, 2007) apresentam a promoção da saúde associada à prevenção de doenças com foco no modelo biológico de saúde. Essa forma de percepção de ações voltadas para prevenção e/ou controle de doenças está enraizado na realidade de se perceber e conduzir ações em um processo saúde-doença como algo curativo (Leite et al., 2015).

Corroborando a esse achado, em um estudo com foco em escolas promotoras da saúde foi observado que $50 \%$ dos seus participantes relacionaram promoção da saúde exclusivamente com hábitos de higiene e $40 \%$ com o repasse de informações sobre higiene. Sendo assim, 91\% dos professores participantes relacionaram a educação em saúde com higiene, dando foco ao cuidado em saúde com ações higienistas (Cardoso et al., 2008). Dessa forma, muitos profissionais ainda se equivocam ao tratar hábitos saudáveis, educação em saúde e prevenção de doenças como sinônimos de promoção da saúde.

No entanto, quatro (20\%) publicações (Costa et al., 2013; Oliveira et al., 2015; Pinheiro, Medeiros, Monteiro \& Simpson, 2015; Gonçalves, Catrib, Vieira \& Vieira, 2008), relacionaram promoção da saúde com qualidade de vida e educação em saúde. Vale ressaltar que os termos promoção da saúde e qualidade de vida surgem constantemente inter-relacionados. A qualidade de vida foi considerada atributo essencial para o desenvolvimento de promoção da saúde (Costa et al., 2013).

Quanto à articulação de promoção da saúde e educação em saúde, esta última é apontada como importante estratégia para alcance de indicadores positivos, no que diz respeito à promoção da saúde entre escolares. Em um estudo com projetos desenvolvidos por professores, foi elencado temas cotidianos e operacionalizado ações voltadas à educação em saúde e à potencialização da vida. Esta proposta contribuiu para uma perspectiva pedagógica de ensinar os escolares a construir competências, nos planos pessoal-individual, social e ecológico, relevantes para a saúde (Oliveira et al., 2015). Portanto, a educação em saúde vinculada à promoção da saúde pode facilitar o desenvolvimento de aspectos do cuidado de si e do outro, respeito, inclusão e promoção da saúde.

\section{Planejamento das ações de promoção da saúde}

A partir dos achados, ficou evidenciada uma importante fragilidade na integração e vínculo entre saúde e educação, o que reflete na dificuldade de desenvolvimento de ações intersetoriais. Nesse contexto, dez (50\%) artigos (Farias et al., 2016; Silva et al., 2014; Leite et al., 2015; Costa et al, 2013; Faia et al., 2013; Medeiros, Pinto, Paiva, Nascimento, Rebouças \& Silva, 2018; Paz et al.; 2018; Souza, Del-Rios, Munari \& Weirich, 2008; Felipe \& Gomes, 2010; Santos \& Bógus, 2007) trouxeram essa questão com um ponto chave.

Em uma investigação quanto a percepção de professores sobre o PSE, os participantes referiram que não há integração entre eles e os profissionais de saúde. Neste cenário, as atividades educativas e sua relação com o programa foram percebidos como avaliações clínicas descontextualizadas (Leite et al., 2015). As interações entre os profissionais de saúde e educação 
ocorrem em casos de necessidade, ou seja, vinculados ao adoecimento das crianças (Faria et al., 2013).

Dessa forma, a relação dos setores saúde e educação apresenta-se como um desafio a ser superado. Pois a intersetorialidade é expressa como premissa para o desenvolvimento das práticas educativas em saúde no ambiente escolar e como elemento facilitador na implantação do PSE (Medeiros et al, 2018). Ressaltam que o PSE no Brasil, prevê a articulação entre a escola, unidade de saúde e a comunidade. Existindo o desafio para as equipes de ambas as instituições de estreitarem laços e firmarem parcerias com ações colaborativas nas escolas (Paz et al., 2018). No entanto, parece que esta relação está desgastada, uma vez que muitas vezes está inserida em um conflito de interesses e deficiência de comunicação, as parcerias acabam se tornando pontuais, e limitam-se ao desenvolvimento de ações com o foco na prevenção e controle de riscos (Farias et al., 2016; Silva et al., 2014).

Quanto a atuação da escola, uma pesquisa relata que $61 \%$ dos professores nunca realizaram nenhuma prática educativa em saúde com os alunos no ambiente escolar (Souza et al., 2008). Para alguns professores, a promoção da saúde está vinculada apenas as ações desenvolvidas pelo setor saúde, negando muitas vezes, as possibilidades de ações coletivas entre os diversos setores a exemplo da educação, habitação, saneamento, dentre outros (Costa et al., 2013).

Vale ressaltar no que tange a participação da saúde, um destaque para o papel dos enfermeiros, reforçando seu grande potencial nas ações educativas com foco na promoção da saúde de escolares. Visto que são frequentemente os profissionais de saúde mais próximos da escola e da comunidade, podendo auxiliar e oferecer práticas educativas em saúde por meio do seu papel ativo (Silva et al., 2014).

Há estudos que sugerem a participação do enfermeiro como educador de saúde nesse processo de transformação da escola, a partir do seu aparato técnico-científico para desenvolver programas, visando a promoção da saúde (Felipe \& Gomes, 2010). Pois considera-se que o enfermeiro traz em sua formação, conteúdos, competências e habilidades que o tornam capaz de atuar em atividades de planejamento em saúde e com o dever de conhecer, exigir e sugerir melhorias referentes à saúde.

Assim, a educação em saúde configura uma importante oportunidade de atuação do enfermeiro, no sentido de promover a saúde e contribuir para a autonomia dos educandos. Entretanto, é importante ressaltar que estas ações devem ser operacionalizadas de modo horizontalizado, com base na escuta ativa e no relacionamento humanizado, superando a mera transmissão de conteúdos. Portanto, é imprescindível que este profissional identifique os conhecimentos prévios daqueles com os quais será realizada a ação de educação em saúde (Pinheiro et al, 2015).

Para tal, é preciso criar vínculos e envolver os setores da educação e da saúde, respeitando os diferentes saberes e necessidades. Desta forma, o diálogo será facilitado, pois favorecerá um melhor relacionamento entre os sujeitos e a valorização das suas necessidades. Pois cabe a enfermagem adquirir novas competências complementares para utilização de abordagem inovadora no processo de ensino-aprendizagem. Dessa forma, poderá envolver os sujeitos como atores no processo educativo da promoção de saúde (Rosa, Campos, Oliveira \& Adão, 2017).

Da mesma forma que o vínculo estabelecido é precário, o planejamento das ações de promoção da saúde no ambiente escolar mostrou-se irregular ou inexistente. Nesse contexto, seis (30\%) artigos (Leite et al., 2015; Cardoso et al., 2008; Costa et al., 2013; Faria et al., 2013; Nothaft et al., 2014; Santos \& Bógus, 2007) demonstraram falta de regularidade ou inexistência de planejamento.

Estudos revelaram que não foi detectada a existência de uma etapa de planejamento coletivo de ações de promoção da saúde, sendo este realizado por iniciativas particulares e de forma desarticulada. Sinalizando assim, lacunas no que se refere a planejamentos internos das ações de práticas de saúde desenvolvidas, sendo indicados pelos autores, a necessidade de aprimoramentos das fases de elaboração das atividades, a partir de planejamentos reais para tentar tornar as ações mais eficazes (Costa et al., 2013; Nothaft et al., 2014). Profissionais de saúde e educação consideram importante a abordagem da promoção da saúde no ambiente escolar. Contudo, afirmaram que ainda não existe uma regularidade de oferta de orientação ou 
planejamento adequado na rotina desses serviços. Quando o planejamento acontece, é baseado em datas comemorativas e campanhas pontuais, atrelando esse tipo de iniciativa apenas ao setor saúde (Costa et al., 2013; Faria et al., 2013).

A maioria dos professores exclui-se do processo de planejamento e execução, atribuindo esse papel ao diretor e ao coordenador pedagógico. Assim, sua atuação é marcada pela realização de tarefas, definidas pelos que ocupam outras funções, caracterizando um distanciamento entre as atividades de planejamento e as de ação (Faria et al., 2013).

Dessa forma, compreende-se que há a necessidade de articular além de ações pontuais outras ações que sejam planejadas e realizadas durante todo o ano letivo por meio de práticas interdisciplinares e intersetoriais estabelecendo fluxos e ações contínuas entre a Saúde e a Educação. Assim, a proposta é que se realize um trabalho contínuo, que faça parte do cronograma de atividades curriculares das escolas, como temas transversais, que abordem à saúde de forma positiva com enfoque na qualidade de vida (Cardoso et al., 2008).

Com a falta de interação entre os setores saúde e educação e a consequente falta de planejamento, não há a identificação das necessidades antes da realização das práticas, três (15\%) artigos (Leite et al., 2015; Cardoso et al., 2008; Santos \& Bógus, 2007) reforçaram essa problemática, trazendo uma tendência à visão assistencialista, que se baseia na preocupação com o cuidado pontual, sem, muitas vezes, considerar condições histórico-sociais da comunidade escolar (Santos \& Bógus, 2007). Apenas dois (10\%) artigos (Pinheiro et al., 2015; Santos et al., 2009) citaram que foi realizado o levantamento da demanda antes da realização das ações de promoção da saúde. A identificação dos problemas de saúde dos escolares somente era realizada quando os alunos manifestam sintomas de doenças (Santos et al., 2009). Já outro estudo indica a importância de identificar os conhecimentos prévios daqueles com os quais será realizada a ação de educação em saúde, para que dessa forma possa contribuir para a superação de apenas transmissão de conteúdos (Pinheiro et al., 2015).

Um estudo realizado com educadores refere que a maneira pela qual a equipe da saúde é inserida a escola, reflete uma ausência por parte dos profissionais de saúde, de uma pesquisa sobre o diagnóstico situacional das necessidades dos adolescentes e uma conversa com os professores sobre qualquer dificuldade ou instalação que encontram diariamente ao abordar questões de saúde na sala de aula. O estudo propõe reuniões no ambiente escolar entre profissionais de saúde e professores para fortalecer as relações e ações de promoção da saúde. Pois o desinteresse dos alunos muitas vezes pode estar relacionado por não saber do que se trata as ações (Leite et al., 2015).

Por muitas vezes os professores culpam a equipe de saúde por não identificarem as necessidades prévias dos educandos, porém também não realizam. Há autores que defendem a capacitação de profissionais da educação para a observação da saúde, desta forma eles conseguiriam perceber a criança em todas as suas necessidades e não só suas doenças. Discussões sobre qualidade de vida, assim como condicionantes e determinantes de saúde poderiam oferecer subsídios aos professores para aguçarem sua percepção (Cardoso et al., 2008).

Quanto a necessidade de inovações tecnológicas no âmbito das práticas do PSE para que se redefina a escola como cenário da promoção da saúde, foi identificada em três (15\%) publicações (Silva et al., 2014; Felipe \& Gomes, 2010; Nothaft et al., 2014), Além disso, foi ressaltado com os achados que ainda não se utiliza uma Tecnologia Educacional para promoção da saúde e muito menos para ações no ambiente escolar.

Estudos refletem que o desenvolver das ações de promoção da saúde no ambiente escolar pode ser dificultado pela falta de recursos didáticos, pedagógicos e tecnológicos. Destacam-se as limitações para pesquisar fontes confiáveis de informações que poderiam fechar a lacuna entre teoria e prática, subsidiando métodos de ensino (Nothaft et al., 2014).

Vale ressaltar que a escolha da abordagem pedagógica e da tecnologia educacional aliado ao contexto e necessidade do público-alvo pode promover melhor efeito no desenvolvimento das práticas educativas na escola. Nesse contexto, chama-se a atenção para o fato de as Diretrizes Curriculares sugerirem o uso de estratégias, métodos e tecnologias participativas, no entanto, as especificidades dessas ações não estão presentes nas ações dos profissionais que as executam (Felipe \& Gomes, 
2010).

Portanto, a utilização de ferramentas tecnológicas no desenvolvimento do processo educativo pode superar o modelo tradicional para o foco da coprodução de saberes e autonomia dos jovens. Permitindo novos arranjos para implementação de ações com vistas à promoção da saúde, em dimensão mais dialógica, interativa e rica de novos saberes, através dos entornos da vida cotidiana dos educandos, profissionais, escola e comunidade. Assim, mesmo reconhecendo a importância da articulação proposta pelo PSE, é preciso avançar em inovações tecnológicas no âmbito das práticas do programa que ressignifiquem a escola como cenário da promoção da saúde numa vertente que considere esse espaço no seu potencial de produção de cidadania e de mudança dos determinantes dos modos de viver (Silva et al., 2014).

\section{Desenvolvimento das ações promoção da saúde nas escolas}

Práticas baseadas no modelo biomédico e no modelo dialógico, emergiram como ações de promoção da saúde a partir dos artigos selecionados. Historicamente, as escolas representam espaços importantes utilizados para vivências e práticas em saúde, em sua maioria adotando abordagens desarticuladas, pontuais, reproduzindo o modelo de atenção e prevenção à doença, perdurando uma lógica higienista (Costa et al., 2013).

Nesse contexto, seis (30\%) artigos (Silva et al., 2014; Leite et al., 2015; Cardoso et al., 2008; Costa et al., 2013; Oliveira et al., 2015; Santos et al., 2007) relataram abordagens tradicionais, pontuais e higienistas em suas ações de promoção da saúde nas escolas. De modo geral, os estudos revelaram a concentração das ações na perspectiva da identificação e controle de riscos e doenças. Além do acentuado enfoque na mudança de comportamento com ações de cunho higienista tais como banho, escovação dos dentes, lavagem das mãos e outros, conforme exemplificado em alguns artigos.

As ações mais citadas para a promoção da saúde foram o desenvolvimento de palestras e avaliações clínicas. Corroborando a esse achado, uma pesquisa relata que as ações educativas na escola e sua relação com o PSE foram percebidas como avaliações clínicas que não se integraram às ações já desenvolvidas na escola com foco apenas em ações de prevenção de doenças com uso predominante de palestras (Leite et al., 2015).

Além disso, foi possível observar que ainda existe uma predominância da concepção especialista, ou seja, a responsabilização do professor de Ciências e de Educação Física nas ações educativas para promoção da saúde. Esses profissionais são considerados no rol de professores como melhor habilitado a desenvolver práticas de educação em saúde, contribuindo assim para ações de promoção da saúde pouco transversais e participativas (Oliveira et al., 2015; Santos et al., 2007).

Quanto às ações de promoção da saúde baseadas no modelo dialógico, cinco (25\%) artigos (Lacerda et al., 2013; Souza et al., 2008; Felipe \& Gomes, 2010; Rabello \& Anderson, 2011; Brandão et al., 2014) trouxeram esse resultado. As ações de promoção da saúde envolveram dinâmicas de grupo, lúdico, teatro, discussões textuais, debates, roda de conversa, mural, música e oficinas. Apoiando esses achados, um estudo sobre práticas pedagógicas cita a retomada de projetos relacionados à área de saúde na proposta curricular da escola, com realização de teatros, músicas, lúdicos, e que dentre as estratégias utilizadas $10,7 \%$ usaram discussões textuais, 7,1\% debates e 7,1\% discussões com os alunos (Souza et al., 2008). Outro estudo aponta que as estratégias dialógicas para tratar determinadas temáticas podem contribuir para a satisfação dos educandos, conforme relatado em uma pesquisa em que mais de $80 \%$ dos educandos participantes avaliaram como muito boa ou boa a utilização de dinâmicas e oficinas (Lacerda et al., 2013).

Em outro estudo, atividades foram desenvolvidas com base em técnicas de dinâmica de grupo, visando não só valorizar a participação do grupo como também um trabalho que dê aos adolescentes o poder da fala, da protagonização, como instrumento singular para uma ação educativa comprometida com a consciência crítica da realidade e o empoderamento dos atores envolvidos (Rabello et al., 2011; Brandão et al., 2014). Dessa forma, o diálogo assume um lugar de elemento mediador, 
atua na formação e transformação de conhecimentos e o processo de ensino-aprendizagem acontece a partir do diálogo entre educadores e educandos, onde ambos fazem trocas, sem fragmentos, dentro ou fora do ambiente escolar e por isso é dialético (Fernandes, Oliveira \& Matta, 2021).

Salienta-se que as ações de saúde que visam a promoção da saúde no espaço escolar devem favorecer uma ação mais reflexiva e crítica do conceito de saúde, sendo mais amplo do que somente ações pontuais, curativas e higienistas, havendo investigação de demandas e temas pertinentes à comunidade escolar e particularmente aos escolares. Assim, reforça-se a necessidade dos profissionais da educação e da saúde em aplicar estratégias educacionais, extrapolando as práticas educativas em saúde baseada em ações pontuais e que não valorizam as verdadeiras necessidades, desejos e aspirações de seus integrantes.

Vale ressaltar que cinco (25\%) artigos (Faria et al., 2013; Souza et al., 2008; Nothaft et al., 2014; Antunes, Antunes \& Corvino, 2008; Gonçalves et al., 2008) citaram o desenvolvimento de práticas baseadas ora no modelo biomédico e ora no modelo dialógico. Assim, pode-se pensar que os modelos se complementam, respondendo positivamente aos programas de educação em saúde e atividades integradas ora utilizando práticas mais tradicionais e ora mais progressistas, tais como: debates, discussões em grupo, palestras e oficinas (Antunes et al., 2008).

Por fim, observa-se que em um estudo, que o cuidado foi considerado pela equipe pedagógica, como elemento presente no trabalho de promoção da saúde na educação infantil (Gonçalves et al., 2008). O que pode refletir na existência de uma mudança gradual no entendimento e necessidade de desenvolver ações de promoção da saúde por meio de ações participativas e que prezem pela autonomia e visão crítica dos estudantes.

\section{Considerações Finais}

A comunidade escolar é um ambiente de cuidar em saúde viável na concretização de ações de promoção da saúde. A realização de ações educativas em saúde nas escolas é determinante nos processos de promoção em saúde, ao desencadear ações, promover discussões, estimular debates e apresentar perspectivas em relação aos processos de saúde e doença, além de fortificar as relações sociais entre profissionais da educação e da saúde.

No entanto, apesar de avanços na saúde escolar, o planejamento insipiente das ações de promoção da saúde nas escolas ressalva aspectos que incentivam o desenvolvimento de ações pontuais, descontextualizadas, normativas, prescritivas e discutidas por áreas do conhecimento focadas nas questões biológicas. Mantendo a relação entre saúde e educação fundamentada no modelo biomédico e no controle de doenças, não favorecendo o alcance da promoção da saúde.

Assim, reforça-se a necessidade dos profissionais da educação e da saúde aplicarem estratégias educacionais que valorizem as verdadeiras necessidades, desejos e aspirações de seus integrantes. Portanto, propõe-se que seja considerada a utilização de tecnologias educacionais que facilitem e potencializem o planejamento e execução de ações de promoção da saúde no espaço escolar de forma sistematizada, articulada e contextualizada.

Dessa forma, este estudo contribui para o aprimoramento das ações educativas em saúde na escola, subsidiando o cuidado em saúde com escolares, incentivando a atuação de profissionais da saúde e da educação para além dos professores de educação física e ciências biológicas, visando a transversalidade da promoção da saúde. Além disso, o estudo pode ampliar as possibilidades para enfermagem a partir da sua atuação no contexto escolar. Visto que reforça o fato de que uma vez as ações de promoção na saúde na escola incluídas na prática do Enfermeiro, podem gerar implicações importantes para a prática de enfermagem pensando no Enfermeiro como agente colaborador e transformador, a fim de realizar uma prática educativa em saúde com compromisso e responsabilidade social a partir de uma atuação multiprofissional.

A principal limitação deste estudo configurou-se, no déficit de artigos produzidos por investigações controladas com maior rigor no delineamento metodológico, as quais permitem maiores comparações e extrapolamentos dos resultados obtidos 
por meio da Revisão Integrativa.

Nesse sentido, é indispensável que ocorram mais estudos envolvendo a presente temática para a ampliação das evidências e com um enfoque na utilização de tecnologias educacionais que possibilitem incrementar e facilitar o planejamento e execução de práticas de promoção da saúde no espaço escolar, estimulando os profissionais da saúde e da educação a se articularem e planejarem, levando em consideração o contexto, a sustentabilidade e a repercussão das práticas. Para que assim, juntamente com o conhecimento obtido neste estudo, possam potencializar a elaboração de políticas públicas e mudanças nas práticas educativas em saúde na escola.

\section{Referências}

Antunes, L. S., Antunes, L. A. A., \& Corvino, M. P. F. (2008). Educative practices and atitudes within the pre-school environment: evaluating the education professional. Braz. oral res., 22(4), 340-345. https://doi.org/10.1590/S1806-83242008000400010

Brandão Neto, W., Silva, A. R. S., Almeida Filho, A. J., Lima, L. S., Aquino, J. M., \& Monteiro, M. L. M. (2014). Educational intervention on violence with adolescents: possibility for nursing in school contexto. Esc. Anna Nery Rev. Enferm., 18(2), 195-201. https://doi.org/10.5935/1414-8145.20140028

Cardoso, V., Reis, A.P., \& Iervolino, S.A. (2008). Escolas Promotoras de Saúde. Rev Bras Crescimento Desenvolv Hum.,18(2), 107-115. http://dx.doi.org/10.7322/jhgd.19872

Costa, G. M. C., Cavalcanti, V. M., Barbosa, M. L., Celino, S. D. M., França, I. S. X., \& Sousa, F. S. (2013). Promoção de saúde nas escolas na perspectiva de professores do ensino fundamental. Rev. eletrônica enferm., 15(2), 506-515. http://dx.doi.org/10.5216/ree.v15i2.15769

Faria, F. H. P., Aguiar, A. C., Moura, A. T. M. S., \& Souza, L. M. B. M. (2013). Percepções de profissionais de saúde da família e de educação sobre a promoção da saúde no ambiente escolar. Rev APS, 16(2), 158-164. https://periodicos.ufjf.br/index.php/aps/article/view/15170

Farias, I. C. V., Ronice, M. P. F., Figueiredo, N., \& Menezes Filho, A. (2016). Análise da Intersetorialidade no Programa Saúde na Escola. Rev. bras. educ. méd., 40(2), 261-267. http://dx.doi.org/10.1590/1981-52712015v40n2e02642014

Felipe, I. C. V., \& Gomes, A. M. T. (2010). Addressing Alcohol in the Context of Elementary Education: the Social Imaginary Reconstruction of Teachers. Rev. Latinoam. Enferm., 18(5), 928-935. https://doi.org/10.1590/S0104-11692010000500013

Fernandes, P. P,, Oliveira, K. S., \& Matta, E. R. A. (2021). Alfabetização sob a perspectiva de Paulo Freire. Research, Society and Development, 10(1), 25253409. http://dx.doi.org/10.33448/rsd-v10i1.11383

Galvão, C. M. (2006). Editorial: Evidence Hierarchies. Acta paul. enferm., 19(2). https://doi.org/10.1590/S0103-21002006000200001

Gonçalves, F. D., Catrib, A. M. F., Vieira, N. F. C., \& Vieira, L. J. E. S. (2008). A promoção da saúde na educação infantil. Interface comum. saúde educ., 12(24), 181-192. doi: https://doi.org/10.1590/S1414-32832008000100014

Lacerda, A. B. M., Soares, V. M. N., Goncalves C. G. O., Lopes F. C., \& Testoni R. (2013). Educational workshops as a strategy to promote hearing heath in adolescents: an exploratory study. Audiol., Commun. Res., 18(2), 85-92. http://dx.doi.org/10.1590/S2317-64312013000200006

Leite, C. T., Machado, M. F. A. S., Vieira, R. P., Marinho, M. N. A. S. B., \& Monteiro, C. F. S. (2015). The school health program: teachers' perceptions. Invest. educ. enferm., 33(2), 280-287. http://dx.doi.org/10.17533/udea.iee.v33n2a10

Luquez, T. M. S., \& Sabóia, V. M. (2017). Prácticas educativas ensalud em la escuela: una revisión integrativa. Cult. Cuid., 21(47), 175-184. https://doi.org/10.14198/cuid.2017.47.15

Marques, E. S. A.,\& Carvalho M. V. C. (2017). Prática educativa bem-sucedida na escola: reflexões com base em L. S. Vigotski e Baruch de Espinosa. Rev. bras. Educ, 22 (71), e227169. http://dx.doi.org/10.1590/s1413-24782017227169

Medeiros, E. R., Pinto, E. S. G., Paiva, A. C. S., Nascimento, C. P. A., Rebouças, D. G. C., \& Silva, S. Y. B. (2018). Facilidades e dificuldades na implantação do Programa Saúde na Escola em um município do nordeste do Brasil. Rev cuid., 9(2), 2127-2134. doi: http://dx.doi.org/10.15649/cuidarte.v9i2.514

Mendes, K. D. S., Silveira, R. C. C. P., \& Galvão, C. M. (2008). Integrative literature review: a research method to incorporate evidence in health care and nursing. Texto \& contexto enferm., 17(4), 758-764. http://dx.doi.org/10.1590/S0104-07072008000400018

Nothaft, S. C. S., Zanatta, E. A., Brumm, M. L. B., Galli, K. S. B., Erdtmann, B. K., Buss, E., \& Silva, P. R. R. (2014). Educators’ perspective on adolescente sexuality: possible education practices. REME rev. min. enferm., 18(2), 290-294. http://dx.doi.org/10.5935/1415-2762.20140022

Oliveira, V. J. M., Martins, I. R., \& Bracht, V. (2015). Projetos e práticas em educação para a saúde na educação física escolar: possibilidades!. Rev. educ. fis., 26(2), 243-255. http://dx.doi.org/10.4025/reveducfis.v26i2.25600

Paz, F. P., Teixeira, V. A., Pinto, R. O., Andersen, C. S., Fontoura, L. P., Castro, C. C., Pattussi, M. P., \& Horta, R. L. (2018). School health promotion and use of drugs among students in Southern Brazil. Rev. Saúde Públ., 52(58), 1-11. https://doi.org/10.11606/s1518-8787.2018052000311

Pereira, A. S., Shitsuka, D. M., Parreira, F. J, \& Shitsuka, R. (2018). Metodologia da pesquisa científica. Rio Grande do Sul: UFSM, NTE. https://repositorio.ufsm.br/bitstream/handle/1/15824/Lic_Computacao_Metodologia-Pesquisa-Cientifica.pdf?sequence=1 
Research, Society and Development, v. 10, n. 1, e57110112112, 2021

(CC BY 4.0) | ISSN 2525-3409 | DOI: http://dx.doi.org/10.33448/rsd-v10i1.12112

Pinheiro, M. G. C., Medeiros, I. B. G., Monteiro, A. I., \& Simpson, C. A. (2015). The nurse and the theme of leprosy in the school context: case studies. $J$. res.: fundam. care., 7(3), 2774-2780. https://doi.org/10.9789/2175-5361.2015.v7i3.2774-2780

Rabello, N., \& Anderson, M. I. P. (2011). Hábitos alimentares e prática de atividade física em escolares: relato de uma experiência de educação em saúde. Rev APS., 14(2), 239-249. https://periodicos.ufjf.br/index.php/aps/article/view/14404

Rosa, E. F. T., Campos, I. C. M., Oliveira, E. C., \& Adão, I. C. (2017). Considerações sobre a Enfermagem na escola e suas práticas educativas. Revista HOLOS, 33(5), 360-369. doi: https://doi.org/10.15628/holos.2017.3644

Santos, I. G., Penna, C. L., Moriyama, F. M., Leão, F. V., Souza, M. P. D., \& Aguiar, Z. N. (2009). Percepção dos educadores e coordenadores de uma creche sobre processo educativo em saúde desenvolvido com abordagem multiprofissional. Rev APS, 12(4), 409-419. https://periodicos.ufjf.br/index.php/aps/article/view/14196

Santos, K. F., \& Bógus, C. M. (2007). A percepção de educadores sobre a Escola Promotora de Saúde: um estudo de caso. Rev Bras Crescimento Desenvolv Hum., 17(3), 123-133. https://doi.org/10.7322/jhgd.19854

Silva, K., Sena, R. R., Gandra, E. C., Matos, J. A. V., \& Coura, K. R. A. (2014). Health promotion in the school health programme and nursing inclusion. REME rev. min. enferm., 18(3), 614-622. http://dx.doi.org/10.5935/1415-2762.20140045

Souza, M. M., Del-Rios, N. H. A., Munari, D. B., \& Weirich, C. F. (2008). Orientação sexual: conhecimentos e necessidades de professores de um Colégio Público de Goiânia-GO. Rev. eletrônica enferm., 10(2), 460-471. http://dx.doi.org/10.5216/ree.v10i2.8047 